\title{
Bone Marrow Necrosis - A rare clinicopathologic entity
}

Binay Kumar Shah, ${ }^{* a}$ David M. Tretheway ${ }^{b}$

${ }^{a}$ Consultant Hematologist and Medical Oncologist, ${ }^{b}$ Consultant Pathologist St. Joseph Regional Medical Center, Lewiston ID USA

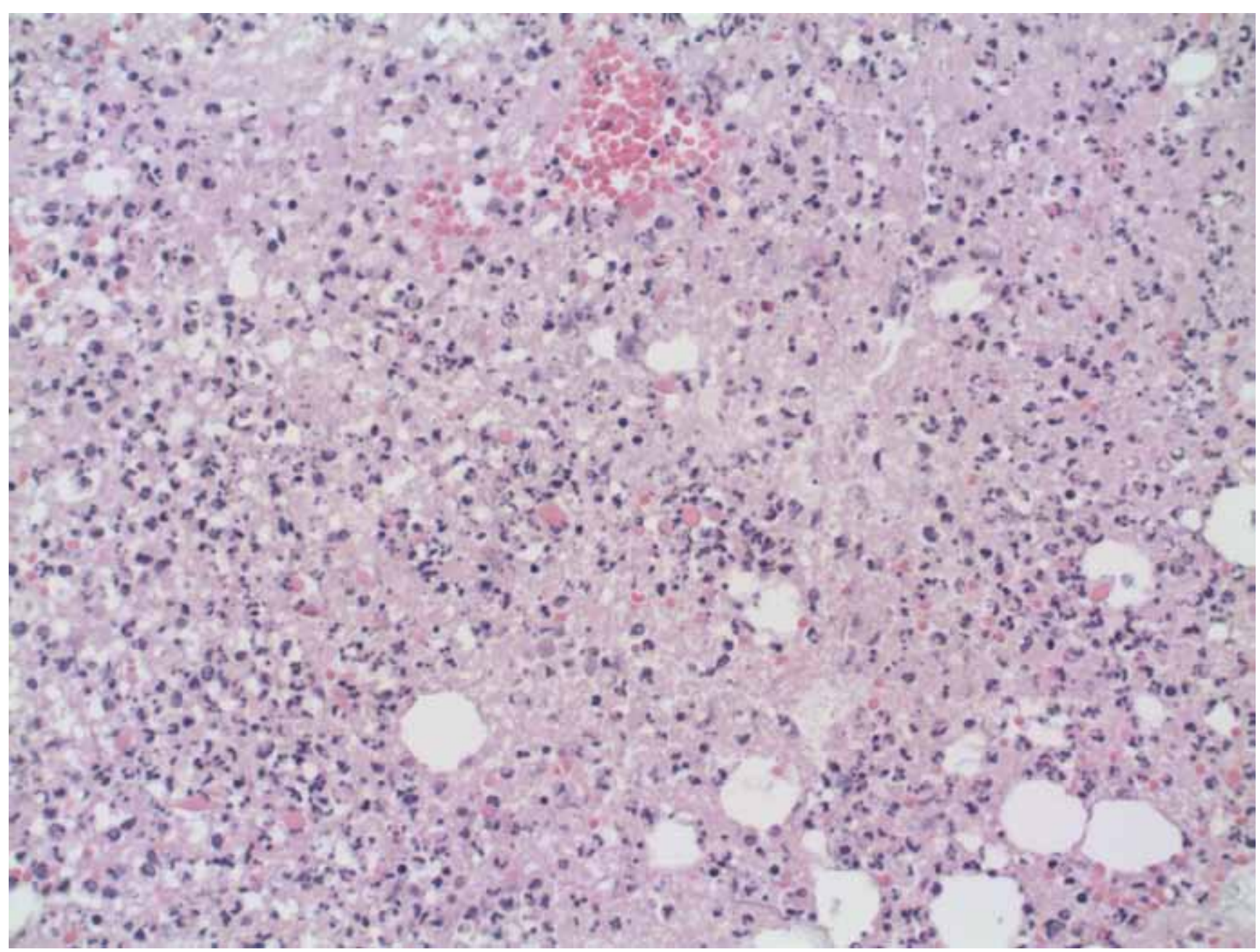

Figure 1. Bone marrow necrosis, ghost cells with acute inflammation and macrophages

\section{Keywords}

Bone marrow necrosis, malignancy

\section{Citation}

Shah BK, Tretheway DM. [Image] Bone Marrow Necrosis - A rare clinicopathologic entity. Journal of Advances in Internal Medicine. 2012;01(1)19.

\section{${ }^{*}$ Corresponding author}

Hematologist and Medical Oncologist

St. Joseph Regional Medical Center, 1250 Idaho

Street, Lewiston ID USA 99403

Email address - binay.shah@gmail.com
CASE

A 76-year-old female presented to the hematology clinic for evaluation of new onset anemia and thrombocytopenia found on routine blood work. Her complaints were severe generalized body pain and easy bruising of approximately 4 weeks duration. She denied any fever or fatigue. On physical examination, she was hemodynamically stable and afebrile. There was no lymphadenopathy or hepatosplenomegaly.

Laboratory examination showed anemia with hemoglobin $7.9 \mathrm{gm} / \mathrm{dl}$, platelet count of $28000 /$ microliter, LDH 1187 u/liter, ferritin 13409 ng/ml and alkaline phosphatase $503 \mathrm{U} / \mathrm{L}$.

Peripheral blood smear showed $2 \%$ blasts with auer rods. Flow cytometry confirmed presence of myeloid blasts in the peripheral blood. Bone marrow aspiration yielded dry tap. Histopathology on bone marrow biopsy is shown below (figure). What is your diagnosis?

Answer - page 26 